Vol. 7 (1) : 69 - 78

\title{
IDENTIFIKASI JENIS POHON FAMILI PODOCARPACEAE PADA HUTAN PEGUNUNGAN ATAS DI GUNUNG BAWANG KABUPATEN BENGKAYANG KALIMANTAN BARAT
}

(Identification of the Species of Family Podocarpaceae Trees in the Upper Mountain Forest in Mount Bawang Bengkayang Regency, West Kalimantan)

\author{
Andre Ronaldo, Hari Prayogo, Muflihati \\ Fakultas Kehutanan Universitas Tanjungpura Pontianak, Jl. Daya Nasional Pontianak 78124 \\ Email : andresylva96@gmail.com
}

\begin{abstract}
Mount Bawang is one of the protected forest areas in Bengkayang Regency, West Kalimantan with an altitude reaching 1.471 masl. Mount Bawang belongs to the type of tropical rain forest which is overgrown by various species of plants with high species diversity. The forest in Gunung Bawang has a zone of upper mountain forest vegetation which is a habitat for tree species from the family Podocarpaceae. Podocarpaceae family tree species can grow in humid forest conditions, dominating the upper mountain forests, mountainous scrublands, and some in the swamp and scorch forest. The purpose of this study was to identify and describe the morphology of tree species from the Podocarpaceae family on Mount Bawang. The method used in this study is an exploration method that is carried out by exploring the ridge at an altitude of 1.100-1.400 masl, then taking samples of the herbarium. Based on the results of the study found 5 species of trees from the family Podocarpaceae. These species are Dacrydium xanthandrum, Falcatifolium falciforme, Podocarpus borneensis, Podocarpus neriifolius, and Phylocladus hyphophyllus. The morphological characteristics of the Podocarpaceae family are generally needle-leafed, leafy mesophyll, thick, upright stems sometimes bent, and have seed-bearing organs in the form of conifers.
\end{abstract}

Keyword: Bengkayang Regency, Mount Bawang, Podocarpaceae, Upper Mountain Forest.

\section{PENDAHULUAN}

Gunung Bawang merupakan salah satu kawasan hutan lindung di Kalimantan Barat dengan ketinggian mencapai $1.471 \mathrm{mdpl}$, yang merupakan salah satu ekosistem pegunungan hutan hujan tropis. Gunung Bawang memiliki keanekaragaman jenis pohon yang relatif tinggi, diantaranya adalah Belian (Eusideroxylon zwageri), meranti/tengkawang (Shorea spp), medang (Litsea spp), keruing (Dipterocarpus coriaceus), cempedak hutan (Artocarpus spp), dan jenis-jenis tumbuhan hias seperti anggrek (Thecopus sp) dan keladi hias (alocasia $s p$ ), serta masih banyak lagi jeni-jenis tumbuhan hutan hujan tropis lainnya (Marega, 2016). Hutan di Gunung Bawang terdapat juga zona vegetasi hutan pegunungan atas yang sangat menarik untuk dipelajari. Zona vegetasi hutan pegunungan atas di gunung bawang dapat ditemukan mulai dari ketinggian $1.100 \mathrm{~m}$ dpl hingga ke puncak gunung, ditandai dengan hutan berlantai lumut yang lembab dan didominasi oleh 
pohon-pohon kerdil, berdaum jarum, batang berbengkok, dengan kondisi tanah yang miskin hara.

Hutan tropis pegunungan atas dapat ditemukan pada ketinggian antara ketinggian 500-4.000 m dpl, dan sebagian besar terdapat pada ketinggian 1.500-2.800 m dpl. Kepulauan di daerah tropis, misalnya di kepulauan Karibia, hutan tropis pegunungan dapat ditemukan pada ketinggian $300 \mathrm{~m}$ dpl (Kapelle, 2004). Hutan pegunungan atas didominasi oleh pohon mikrofil (berdaun kecil) dengan permukaan kanopi rata dan pohon-pohon yang ramping berbatang bengkok dan tajuk pohon yang rapat. Flora hutan pegunungan atas lebih miskin dari flora pegunungan bawah. Marga-marga yang umum antara lain adalah Dacrycarpus, Daphniphyllum, Drimys, Elaeocarpus, Eurya, Myrsine, Papuacedrus, Pittosporum, Podocarpus, Quintinia, Saurauia, dan Symplocos (Whitmore, 1984).

Jenis-jenis tumbuhan yang sering dijumpai pada tipe hutan pegunungan atas adalah anggota suku Ericaceae, seperti Rhododendron, Vaccinium, dan Gaultheria, serta jenis lainnya seperti Aristatus piperata dan Phyllocladus hypophyllus (Widjaja, 2014). Famili Podocarpaceae juga sangat mendominasi pada hutan pegunungan atas, bahkan ditemukan pada hutan sub alpine seperti Dacrycarpus kinabaluensis di Gunung Kinabalu. Ditribusi podocarpaceae tidak bisa dilihat dari ketinggian saja karena pada hutan tropis hutan pegunungan atas di
Kalimantan bisa ditemukan pada ketinggian yang lebih rendah (Enright, 2011). Menurut Cernusak (2011) jenisjenis dari famili podocarpaceae merupakan jenis-jenis khas pada hutan hujan tropis pegunungan atas.

Famili podocarpaceae terdiri dari 18 genus dan sekitar 173 spesies, berupa pohon dan semak. Famili ini merupakan gymnospermae yang paling mendominasi di hutan hujan tropis. Penyebaran Podocarpaceae terutama di Belahan Bumi Selatan kemudian membentang ke Utara seperti Cina dan Jepang, kemudian sampai ke Meksiko dan Karibia. Jenis-Jenis dari famili Podocarpaceae dapat tumbuh pada kondisi hutan yang lembab, sangat jarang ditemukan di dataran rendah dan hutan tropis pegunungan bawah, namun sangat mendominasi pada hutan pegunungan atas, semak belukar pegunungan, dan beberapa pada hutan rawa dan kerangas (Biffin, dkk, 2011). Ciri umum dari famili podocarpaceae adalah berdaun jarum, berdaun mesofil, dan organ pembawa biji berupa runjung (Laubenfels, 1988).

Penelitian ini bertujuan untuk mengidentifikasi dan mendeskripsikan morfologi jenis-jenis pohon famili podocarpaceae pada zona vegetasi hutan pegunungan atas di Kawasan Hutan Lindung Gunung Bawang Kabupaten Bengkayang Kalimantan Barat. Manfaat penelitian ini adalah tersedianya data dan informasi mengenai jenis-jenis pohon famili podocarpaceae pada zona vegetasi hutan pegunungan atas di Hutan Lindung Gunung Bawang sehingga dapat 
membantu dalam pengelolaan Hutan Lindung Gunung Bawang. Data dan informasi mengenai penelitian ini juga sangat diperlukan sebagai dasar untuk penelitian-penelitian selanjutnya, dijadikan bahan pembelajaran dibidang kehutanan, serta menambah catatan koleksi flora khususnya jenis-jenis pohon famili Podocarpaceae pada hutan pegunungan di Kalimantan Barat.

\section{METODOLOGI PENELITIAN}

Penelitian ini dilaksanakan pada Zona Vegetasi Hutan Pegunungan Atas di Hutan Lindung Gunung Bawang, Kabupaten Bengkayang, Kalimantan Barat, dengan waktu pelaksanaan selama 2 minggu efektif di lapangan. Alat dan bahan yang digunakan dalam penelitian ini adalah peta lokasi penelitian, kamera, GPS, phyband, hagameter, peralatan pengumpulan spesimen, peralatan pembuatan herbarium dan buku Identifikasi Flora Malesiana Series 1 Volume 10 (Laubenfels, 1988). Objek dalam penelitian ini adalah semua jenis pohon famili Podocarpaceae yang terdapat pada lokasi penelitian.

Metode yang digunakan adalah metode eksplorasi yang dilakukan dengan cara jejalah, yaitu dengan menjelajahi punggung gunung dari ketinggian 1.100-1.400 m dpl, dimana ditemukannya jenis pohon famili Podocarpaceae (Rugayah, 2004). Kemudian diambil koleksi herbarium, pengambilan contoh untuk herbarium diambil dari semua jenis pohon yang ditemukan pada lokasi penelitian dan hanya dilakukan sekali untuk setiap jenisnya. Setiap jenis pohon yang dikoleksi diberi nomor koleksi pada label dan dicatat informasi lapangannya (Randi, 2013). Semua jenis pohon dari famili Podocarpaceae yang ditemukan di lokasi penelitian, diambil contoh herbariumnya, diberi nomor koleksi pada label dan dicatat informasi lapangannya. Analisis data yang digunakan adalah analisis kualitatif. Analisis dilakukan dengan cara mendeskripsikan ciri-ciri morfologi (generatif maupun vegetatif) secara detail pada semua jenis pohon yang ditemukan di setiap jalur penelitian, kemudian dibuat kunci determinasi.

\section{HASIL DAN PEMBAHASAN}

Jenis-jenis pohon dari famili podocarpaceae sangat berlimpah pada hutan pegunungan atas. Kelimpahan jenis Podocarpaceae umumnya meningkat seiring bertambahnya ketinggian gunung. Podocarpaceae sangat jarang ditemukan pada hutan dataran rendah, namun dapat ditemukan kondisi habitat yang miskin hara seperti pada hutan kerangas. Distribusi Podocarpaceae di Pulau Kalimantan tidak terbatas hanya pada hutan pegunungan atas saja, namun jenis ini dapat beradaptasi pada kondisi tanah yang miskin hara, dalam hal ini keberadaannya sangat dipengaruhi oleh kondisi hara tanah. Jenis-jenis Podocarpaceae yang umum di Kalimantan adalah Dacrycarpus imbricatus, Phyllocladus hyphophyllus, Podocarparpus sp dan Dacrydium sp (Kitayama, dkk, 2011).

Berdasarkan hasil eksplorasi ditemukan 5 jenis pohon dari famili 
Podocarpaceae. Jenis-jenis tersebut adalah Dacrydium xanthandrum, Falcatifolium falciforme, Phylocladus hyphophyllus, Podocarpus neriifolius dan Podocarpus borneensis. Keseluruhan jenis tersebut 1 diantaranya merupakan jenis pohon endemik Kalimantan, yaitu Podocarpus borneensis. Adapun deskripsi masingmasing jenis-jenis pohon famili Podocarpaceae yang ditemukan adalah sebagai berikut :

\section{Dacrydium xanthandrum Pilg.}

Deskripsi lapangan : Dacrydium xanthandrum Pilg berupa pohon kerdil. Pohon pada lokasi penelitian ditemukan berukuran tinggi rata-rata $12 \mathrm{~m}$ dan diameter rata-rata $13 \mathrm{~cm}$. Batang lurus kadang berlekuk dan bercabang monopodial, dengan ranting terkulai, tajuk kerucut. Permukaan batang kadang mengelupas dan kasar. Kulit batang berwarna kecoklatan sampai keabu-abuan. Daun seperti bulu-bulu, lurus dan menyempit pada pertumbuhan tunas baru, daun dewasa menyebar luas, lurus, sedikit mengbungkuk ke depan, komposisi daun majemuk, berwarna hijau kekuningan dan agak kecoklatan pada pangkal daun, bentuk daun linear seperti jarum, daun berukuran panjang 5$10 \mathrm{~mm}$ lebar $0,4-0,8 \mathrm{~mm}$ dan tebal 0,2 $\mathrm{mm}$, duduk daun tersebar, tepi daun rata, permukaan atas dan bawah daun rata, ujung daun runcing, pangkal daun runcing, tulang daun sejajar, tidak ada stipule. Buah dan bunga tidak ditemukan.

Menurut De Laubenfels (1988) umumnya Dacrydium xanthandrum berupa pohon. Biasa tinggi pohon mencapai $36 \mathrm{~m}$ dan diameter mencapai $70 \mathrm{~cm}$. Daun jarum, menyebar luas, lurus, membungkuk ke depan. Ukuran daun 6-10 $\mathrm{mm} \times 0,5-0-8 \mathrm{~mm}$ dan tedal $02 \mathrm{~mm}$. Bunga biasanya tumbuh pada ujung daun atau ranting, bunga jantan dan betina telaknya terpisah. Buah berbentuk lonjong terletak diantara tangkai daun. Berdasarkan ekologinya Dacrydium xanthandrum dapat ditemukan pada hutan pegunungan berlumut, gambut, tanah berpasir, hingga ketinggian 1.000-2.700 m dpl. Lokasi penelitian ditemukan pada ketinggian $1.100-1.400 \mathrm{~m}$ dpl. Penyebaran Dacrydium xanthandrum mulai dari Kepulauan Solomon, Malesia, Sabah , Sarawak, Kalimantan Barat, Sulawesi, dan Sumatera. 


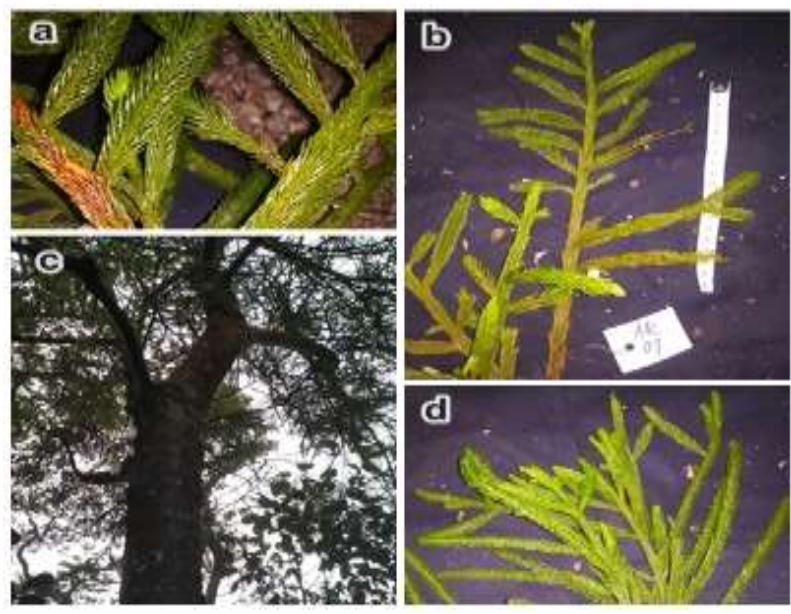

Gambar 1. Dacrydium xanthandrum Pilg. : a. Daun jarum, b. Daun berukuran panjang 5-10 $\mathrm{mm}$ lebar 0,4-0,8 mm, c. Batang, d. Bagian ranting. (a. Acicular leaf, b. Leaves 5-10 $\mathrm{mm}$ by 0,4-0,8 mm, c. Stem, d. Portion of twig).

\section{Falcatifolium falciforme (Parl.) De} Laub.

Deskripsi lapangan : Falcatifolium falciforme (Parl) de Laub berupa pohon kerdil sampai besar. Pohon pada lokasi penelitian ditemukan berukuran tinggi rata-rata $14 \mathrm{~m}$ dan diameter rata-rata $21,5 \mathrm{~cm}$. Batang lurus kadang berlekuk dan bercabang monopodial. Permukaan batang kadang mengelupas dan kasar. Kulit batang berwarna hitam kecoklatan sampai keabu-abuan. Daun melebar secara bertahap, komposisi daun majemuk, berwarna hijau tua, bentuk daun linear, agak melengkung pada ujung daun dan pangkal daunnya, daun berukuran panjang 3-6 cm lebar 5-9 mm, duduk daun berhadapan, susunan anak daun berseling, tepi daun rata, permukaan atas dan bawah daun licin, ujung daun runcing, pangkal daun runcing, tulang daun sejajar, pertumbuhan tunas baru tersebar, tidak ada stipule. Daun dewasa pada cabang pertama ukurannya lebih besar di bandingkan dengan daun lainnya. Cone tidak ditemukan.

Menurut De Laubenfels (1988) umumnya Falcatifolium falciforme berupa pohon. Biasanya tinggi mencapai $36 \mathrm{~m}$, namum lebih umum 5-12 m, dengan diameter mencapai 4-40 cm. Daun linear berukuran 4-7 cm x 5-9 mm, ujung daun runcing dan melengkung, susunan daun berseling dan tersebar di sepanjang ranting daun. Bunga biasanya tumbuh pada ketiak daun, bunga jantan dan betina telaknya terpisah. Cone berbentuk lonjong memanjang, terletak pada ketiak daun. Berdasarkan ekologinya Falcatifolium falciforme umumnya ditemukan pada hutan pegunungan, pada lokasi penelitian ditemukan pada ketinggian 1.100 1.300 m dpl. Penyebaran Falcatifolium falciforme mulai dari Kalimantan, Serawak, Sabah. 


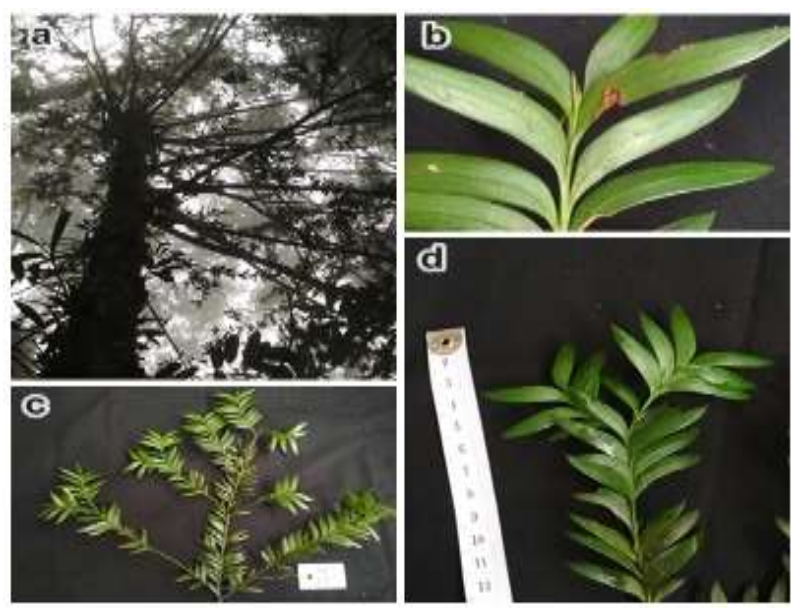

Gambar 2. Falcatifolium falciforme (Parl) de Laub. : a. Batang, b. Bentuk daun linear, c. Bagian ranting, d. daun berukuran 3-6 cm x 5-9 mm. (a. Stem, b. Linear leaf, c. Portion of twig, d. Leaves 3-6 $\mathrm{cm}$ by 5-9 $\mathrm{mm}$ ).

\section{Phyllocladus hyphophyllus Hook.f}

Deskripsi lapangan : Phylocladus hyphophyllus Hook.f berupa pohon kerdil. Pohon pada lokasi penelitian ditemukan berukuran tinggi rata-rata 10 $\mathrm{m}$ dan diameter rata-rata $13 \mathrm{~cm}$. Batang lurus sampai berlekuk, dan bercabang monopodial. Batang mengelupas kecil dan licin. Kulit batang berwarna coklat tua sampai kemerahan. Daun agak tebal, komposisi daun tunggal, berwarna hijau kekuningan, daun berupa phylloclade berbentuk seperti perisai dan agak lonjong dengan ukuran 3-8 cm x 2-3 cm, permukaan atas dan bawah daun licin, ujung daun meruncing, pangkal daun runcing, tepi daun bergelombang, tulang daun sejajar, duduk daun berkarang, tidak ada stipule. Cone terletak di ujung daun, tersusun berseling, berwarna kuning kemerahan.
Menurut De Laubenfels (1988) umumnya Phyllocladus hyphophyllus berupa pohon. Biasanya diameter pohon bisa mencapai $60 \mathrm{~cm}$ dan tinggi mencapai $30 \mathrm{~m}$. Daun bersisik, berupa phylloclade, tepi daun bergelombang, duduk daun berkarang. Bunga tidak memiliki mahkota, hanya berupa strobilus. Strobilus jantan dan betina letaknya terpisah. Berdasarkan ekologinya Phyllocladus hyphophyllus dapat ditemukan pada hutan dataran rendah $900 \mathrm{~m}$ dpl sampai hutan pegunungan $3.200-4.000 \mathrm{~m}$ dpl. Lokasi penelitian ditemukan pada ketinggian 1.200 - 1.400 m dpl. Penyebaran Phyllocladus hyphophyllus mulai dari Filipina, Kalimantan, Sulawesi, Maluku, Papua, dan New Guinea. 

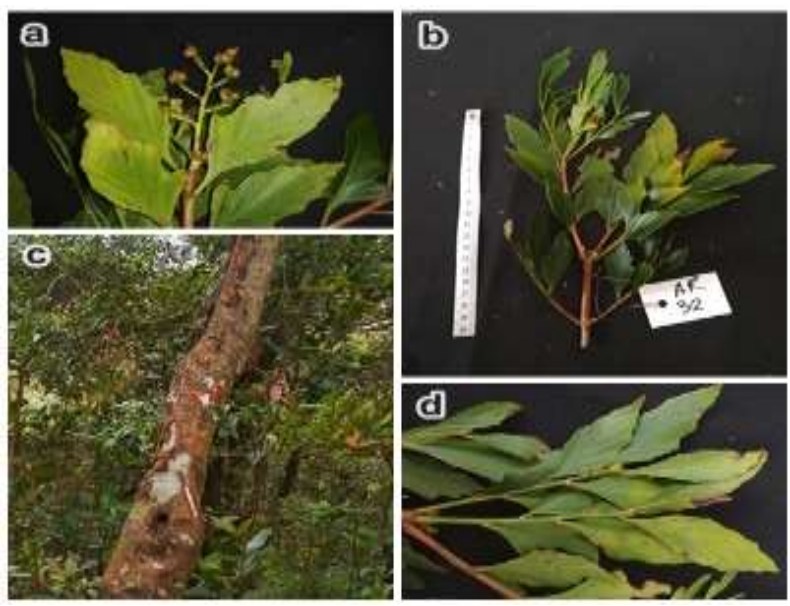

Gambar 3. Phylocladus hyphophyllus Hook.f : a. Organ betina, b. Seranting daun,

c. Batang, d. Daun berukuran 3-8 cm x 2-3 cm. (a. Female cone, b. Foliage, c. Stem, d. Leaves 3-8 $\mathrm{cm}$ by 2-3 cm).

\section{Podocarpus borneensis de Laub.}

\section{Deskripsi lapangan : Podocarpus}

borneensis de Laub berupa pohon.

Pohon pada lokasi penelitian ditemukan berukuran tinggi rata-rata $11 \mathrm{~m}$ dan diameter rata-rata $14 \mathrm{~cm}$. Batang lurus kadang berlekuk, percabangan monopodial, tajuk kerucut. Permukaan batang licin kadang berlekuk. Kulit batang berwarna kecoklatan sampai abuabu. Daun kuncup keatas, tunggal, agak tebal, berwarna hijau muda kekuningan dan agak kemerahan pada pangkal daun, bentuk daun linear memanjang berukuran $5-9 \mathrm{~cm}$ x 1-1,3 cm, duduk daun tersebar, berkarang dan menumpuk pada ujung ranting dekat tunas daun, panjang tunas $7 \mathrm{~mm}$ berwarna kemerahan berbentuk runcing, ranting tersusun berhadapan dan tersebar, tepi daun rata, permukaan atas dan bawah daun licin, ujung daun meruncing, pangkal daun runcing, tulang daun sejajar dan menonjol, ada stipule. Cone tidak ditemukan.

Menurut De Laubenfels (1988) umumnya Podocarpus borneensis berupa pohon. Biasanya tinggi pohon bisa mencapai $23 \mathrm{~m}$ dan diameter pohon mencapai $21 \mathrm{~cm}$. Daun berbentuk linear, berukuran 5-9 $\mathrm{cm} \times$ 0,5-1,3 cm, tersusun berseling dan menumpuk berkarang pada tunas daun. Bunga jantan dan betina terdapat pada pohon berbeda. Bunga jantan tersusun dalam strobilus pada ujung ranting sedangkan bunga betina soliter, bertangkai terletak pada ketiak daun, biji telanjang dibungkus cakram mendaging. Berdasarkan ekologinya Podocarpus borneensis dapat ditemukan pada punggung bukit berbatu yang berlumut, hutan kerangas, rawa, dan pada ketinggian 700-2.070 m dpl. Lokasi penelitian ditemukan pada ketinggian 1.100 - $1.300 \mathrm{~m}$ dpl. Penyebaran Podocarpus borneensis endemik di Kalimantan. 

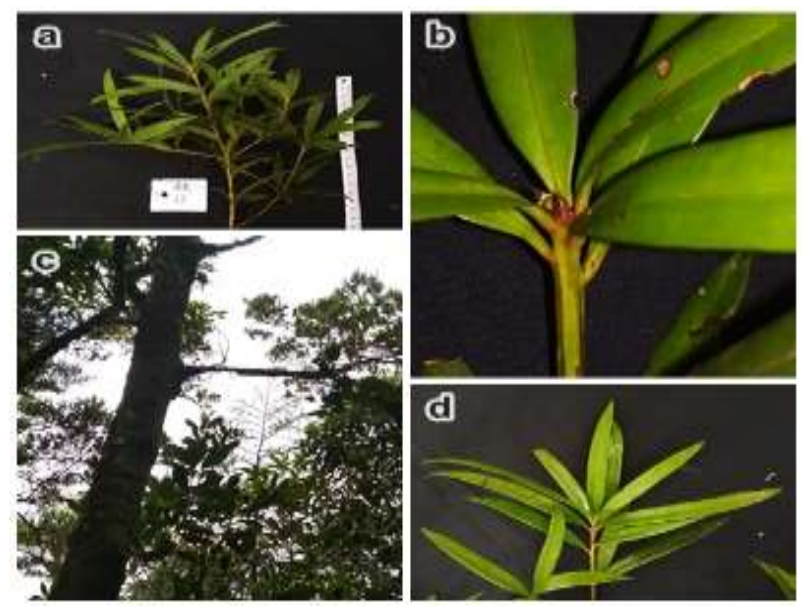

Gambar 4. Podocarpus borneensis de Laub : a. Seranting daun, b. Duduk daun tersebar, c. Batang, d. Daun berukuran 5-9 cm x 1-1,3 cm. (a. Foliage, b. Spiral leaf, c. Stem, d. Leaves 5-9 cm by 1-1,3 cm).

\section{Podocarpus neriifolius D.Don.}

\section{Deskripsi lapangan : Podocarpus} neriifolius D.Don pohon berukuran kecil sampai sedang. Pohon pada lokasi penelitian ditemukan berukuran tinggi rata-rata $12 \mathrm{~m}$ dan diameter rata-rata 16 cm. Batang lurus kadang berlekuk, percabangan monopodial, tajuk kerucut. Permukaan batang licin kadang mengelupas halus. Kulit batang berwarna kecoklatan. Daun tunggal, berwarna hijau tua, bentuk daun linear memanjang berukuran $14-20 \mathrm{~cm}$ x 2-2,4 $\mathrm{cm}$, duduk daun tersebar, berkarang pada ujung ranting disekitar tunas, tunas berbentuk bulat berwarna coklat kehitaman berukuran 2-5 $\mathrm{mm}$. dan tersusun berseling pada ranting, ranting tersusun berhadapan dan tersebar, tepi daun agak bergelombang, permukaan atas dan bawah daun agak kasar, ujung daun meruncing, pangkal daun runcing, tulang daun sejajar, ada stipule. Cone tidak ditemukan.
Menurut De Laubenfels (1988) umumnya Podocarpus neriifolius berupa pohon. Biasanya tinggi pohon berukuran 5-45 $\mathrm{m}$ dan berdiameter 2,5$21 \mathrm{~cm}$. Daun linear, bergelombang, berukuran 14-26 cm x 2,4 cm, tersusun tersebar, menumpuk pada tunas, panjang tunas 2-5 mm. Bunga jantan tersusun dalam strobilus pada ujung ranting sedangkan bunga betina soliter, bertangkai terletak pada ketiak daun, bunga jantan dan betina terdapat pada pohon yang berdeda. Berdasarka ekologinya Podocarpus neriifolius dapat ditemukan pada pegunungan berbatu, hutan berlumut, hutan kerangas, tanah berpasir, pada ketinggian $2.100 \mathrm{~m} \mathrm{dpl}$, sedangkan pada lokasi penelitian ditemukan pada ketinggian 1.100 1.200 m dpl. Penyebaran Podocarpus neriifolius mulai dari Nepal, Thailand, Malesia, Solomon, Fiji, Sumatera, Jawa, Sulawesi, Maluku, dan Kalimantan. 


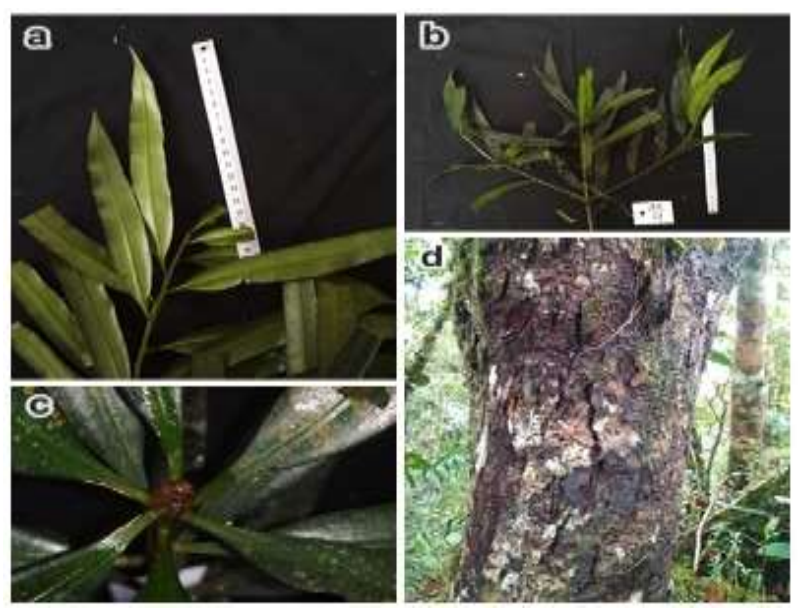

Gambar 5. Podocarpus neriifolius D.Don : a. Daun berukuran berukuran $14-20 \mathrm{~cm}$ x 2-2,4 $\mathrm{cm}, \mathrm{b}$. Seranting daun, c. Duduk daun tersebar, d. Batang. (a. Leaves 14-20 cm by 2-2,4 cm, b. Foliage, c. Spiral leaf, d. Stem).

Kunci determinasi untuk jenis-jenis pohon dari famili Podocarpaceae yang ditemukan pada lokasi penelitian adalah sebagai berikut :

1. a. Daun jarum. Dacrydium xanthandrum

b. Daun lebar, linear.......................................

2. a. Daun tidak sejati berupa Phylloclade...... ..Phyllocladus hyphophyllus b. Daun sejati tidak berupa Phylloclade.......................................................

3. a. Ujung daun melengkung................. Falcatifolium falciforme

b. Ujung daun lurus .4

4. a. Daun berwarna hijau muda, berukuran 5-9 $\mathrm{cm} \times 1-1,3 \mathrm{~cm}$........... Podocarpus borneensis b. Daun berwarna hijau tua, berukuran 14-20 $\mathrm{cm} \times$ 2-2,4 cm.......... Podocarpus neriifolius

\section{KESIMPULAN}

Berdasarkan hasil eksplorasi dilakukan mulai dari ketinggian 1100 mdpl hingga 1400 mdpl ditemukan 5 Jenis pohon dari famili Podocarpaceae. Jenis-jenis tersebut adalah Dacrydium xanthandrum, Falcatifolium falciforme, Phylocladus hyphophyllus, Podocarpus neriifolius dan Podocarpus borneensis. 1 jenis diantaranya merupakan jenis pohon endemik Kalimantan, yaitu Podocarpus borneensis. Kemudian, 1 diantaranya merupakan flora khas hutan hujan tropis pegunungan atas yaitu Phylocladus hyphophyllus. Jenis-jenis dari famili Podocarpaeae sangat mendominasi pada hutan pegunungan atas di Gunung Bawang. Hutan Pegunungan Atas Gunung Bawang memiliki ciri-ciri suhu relatif rendah, miskin unsur hara, hutan lembab berlantai lumut. Hal ini menunjukkan bahwa podocarpaceae mampu beradaptasi dengan kondisi ekstrim pada hutan pegunungan atas.

\section{SARAN}

Hasil penelitian ini diharapkan dapat menambah catatan flora di Gunung Bawangdan dapat dijadikan acuan bagi penelitian-penelitian selanjutnya, selain itu penelitian ini juga dapat dilanjutkan ke gunung-gunung lainnya di Kalimantan Barat agar dapat menambah 
catatan koleksi jenis-jenis pohon famili podocarpaceae pada pegunungan di Kalimantan.

\section{DAFTAR PUSTAKA}

Biffin E, Conran GJ, Lowe JA. 2011. Podocarp Evolution: A Molecular Phylogenetic

Cernusak AL, Adie H, Bellingham JP. 2011. Podocarpaceae in Tropical Forest. Smithsonian Institution Scholarly Press (12): 200-206.

De Laubefels, David J. 1988. Flora Malesiana Series 1 Volume 10: Coniferales. Dordrecht: Kluwer Academic.

Enright JN, Jaffre T. 2011. Ecology and Distribution of the Malesian Podocarps. Smithsonian Institution Scholarly Press (4): 68-88.

Kapelle M. 2004. Tropical Mountain Forest: Regional Forest Type. Oxford: Elsevier.

Kitayama K, Aiba S, Ushio M. 2011. The Ecology of Podocarp in Tropical Forest of Borneo: Distributoin, Populatioun Dynamics, and Soil Nutrient Acquisition. Smithsonian
Institution Scholarly Press (6): 112-128.

Marega, Indrayani Y, Ardian H. 2016. Keanekaragaman Jenis Tumbuhan Berpotensi Menjadi Tanaman Hias pada Kawasan Hutan Lindung Gunung Bawang Kabupaten Bengkayang. Jurnal Hutan Lestari 4(4): 534-542.

Randi A, Manurung TF, Siahaan S. 2013. Identifikasi Jenis-Jenis Pohon Penyusun Vegetasi Gambut di Taman Nasional Danau Sentarum Kabupaten Kapuas hulu. Jurnal Hutan Lestari 3(67): 66-73.

Rugayah, Retnowati A, Windradi FI, \& Hidayat. 2004. Pedoman Pengumpulan Data Keanekaragaman Flora. Bogor: Pusat Penelitian Biologi LIPI.

Whitmore TC. 1984. Tropical Rain Forest of the Far East $2^{\text {nd }}$ edition. Oxford: Oxford University Press.

Widjaja EA. 2014. Kekinian Keanekaragaman Hayati Indonesia. Jakarta: LIPI Press dan Kementrian Lingkungan Hidup 